\title{
Telocyte and Cajal cell distribution in renal pelvis, ureteropelvic junction (UPJ), and proximal ureter in normal upper urinary tract and UPJ obstruction: reappraisal of the aetiology of UPJ obstruction
}

\author{
M. Wishahi' ${ }^{1}$ A.A. Mehena ${ }^{1}$, H. Elganzoury ${ }^{1}$, M.H. Badawy' ${ }^{1}$, E. Hafiz ${ }^{2}$, T. El-Leithy ${ }^{1}$ \\ ${ }^{1}$ Department of Urology, Theodor Bilharz Research Institute, Cairo, Egypt \\ 2Department of Pathology and Electron Microscopy, Theodor Bilharz Research Institute, Cairo, Egypt
}

[Received: 17 August 2020; Accepted: 23 September 2020; Early publication date: 23 September 2020]

\begin{abstract}
Background: Telocytes and Cajal cells have been described in human urinary tract and reproductive system in women and men. Telocytes and Cajal cells have been differentiated from other interstitial cells and were described to be an element in smooth muscle conductivity. Previous studies examined the ureteropelvic junction (UPJ) segment in patients with UPJ obstruction (UPJO) and attributed the aetiology of UPJO to the low density or absence Cajal cells and telocytes. The present work aimed at the demonstration of the presence and the density of telocytes and Cajal cells in the upper urinary tract (UUT) in cases with normal UUT and UPJO. It included UPJ segment, renal pelvis, and proximal ureter. The morphological pattern of distribution of collagen in relation to smooth muscle was investigated in normal and obstructed UUT.
\end{abstract}

Materials and methods: The study was carried out on 12 surgical specimens, 5 of them represented the normal UUT and underwent nephrectomy for oncological reasons. Seven patients underwent dismembered pyeloplasty for UPJO. Surgical specimens included renal pelvis, UPJ segment, and proximal ureter. They were subjected to standard haematoxylin and eosin stain, Gomori's trichrome stain, immunohistochemistry with c-kit, and transmission electron microscopy.

Results: Telocytes and Cajal cells were demonstrated in the muscular layer of both normal UUT and UPJO with high density in the proximal ureter in normal UUT as well as in UPJO. The UPJ segment in normal UUT had moderate density of Cajal cells and telocytes while in UPJO the cells were scanty or absent. Renal pelvis in normal UUT showed excess density of cells while obstructed renal pelvis showed scanty Cajal cells and telocytes. Ultrastructural study showed the presence of Cajal cells, telocytes, stem cells, fibroblasts, smooth muscle cells, and collagen in different densities and distribution in normal and obstructed UUT. Conclusions: Examination of the UPJ segment of UPJO revealed that Cajal cells and telocytes were scanty or absent, collagen to muscle ratio was high. The low density of Cajal cells and telocytes in the renal pelvis of the obstructed UUT, compared to the normal, points out to the role of the renal pelvis in the pathogenesis of UPJO. (Folia Morphol 2021; 80, 4: 850-856)

Key words: Cajal cells, telocytes, ureteropelvic junction, urinary tract, interstitial cells 


\section{INTRODUCTION}

The upper urinary tract is anatomically divided into renal pelvis, ureteropelvic junction (UPJ) and proximal ureter. The three parts have several cellular varieties: smooth muscle cells, blood vessels, and the interstitium of the connective tissues containing several types of interstitial cells: fibroblasts, mast cells, resident macrophages, stem cells, plasma cells, lymphocytes, granulocytes and monocytes, and, in addition, two unique types of interstitial cells: the interstitial like-cells of Cajal (Cajal cells), and telocytes. Telocytes and Cajal cells have been described to be responsible for the transmission of electric activity to smooth muscle cells and for their rhythmic contraction and relaxation. Cajal cells and telocytes were described in the urinary tract and their function is initiation of urine transport. Cajal in 1910 was the first to describe a distinct cell in the gut which was named on him later [1]. Cajal cells were described to be responsible for gut motility. Evidence suggests that Cajal cells' function is the generation of the electrical activities. They are unique cells that either have intrinsic pacemaker activity or are able to perform stimulus-induced pace-making; they act as networks for inhibitory and excitatory functions [9]. Cajal-cells were identified with immunohistochemistry $(\mathrm{IHC})$ as c-kit positive-stained cells and were demonstrated in the human urinary tract [16], upper urinary tract $[6,8]$, ureter [3], urinary bladder [5], and urethra [14]. Interstitial cells of Cajal were demonstrated by transmission electron microscopy (TEM) studies. They are distinct from smooth muscle cells, fibroblasts, and monocytes, the surface membrane has abundant invaginations and prominent endoplasmic reticulum, and they are characterised by being uninucleate with thin cytoplasm and numerous mitochondria $[4,5,7,8,11,19,20]$. Low density or altered function of Cajal cells were attributes to the aetiology of UPJ obstruction [3, 4, 7, 15, 21]. Eken et al. [4] studied UPJ specimens from patients with UPJ obstruction and normal control, examining them with TEM, light microscopy, and IHC stain. They found out that the c-kit positive-stained cells were located near the circular muscle layer and were encountered more frequently in the control group. The ratio of areas with no cells in the UPJ obstruction group was significantly higher when compared to the control group. The working group of Popescu et al. [11, 12] in Romania in the year 2010 described cells which were semi-similar to Cajal cells and named them "telocytes". Telocytes were detected in the urinary system
[22], kidney cortex [13], and urinary bladder [17]. Examination of tissue specimens with TEM would determine the presence of telocytes. The ultrastructural characteristics of the telocytes are their long cytoplasmic processes which are called "telopodes". The telopode is characterised by the alternation of thin tracts with dilations. The thin segments are called podomers and the dilated regions podoms. Podoms have a functional unit consisting of mitochondria, endoplasmic reticulum, and caveolae. The bodies of telocytes vary in shape: fusiform, pyriform, or triangular. The nucleus contains condensed heterochromatin; the surrounding cytoplasm is scarce and encompasses few organelles $[2,10,17,19]$. Ultrastructural features characterising and differentiating telocytes and $\mathrm{Ca}$ jal cells were described in detail by Vannuchi et al. [17-19]. Telocytes were attributed to the aetiology of UPJ obstruction [21]. We investigate the distribution of Cajal, telocytes, interstitial cells, and morphometric pattern of collagen to smooth muscles in normal UUT and UPJ obstruction by using haematoxylin and eosin stain, Gomori's modified Masson's trichrome stain for light microscopy, IHC and TEM.

\section{MATERIALS AND METHODS}

\section{Patients}

Twelve patients were included in the study. Of this total number, 5 patients, who had undergone nephrectomy for oncological reasons, represented the normal upper urinary tract without obstruction. Mean age was $52 \pm 7$ years ( 3 males and 2 females; age range was 44-57 years). They had renal cell carcinoma $>7 \mathrm{~cm}$ located in the periphery of the kidney, preoperative imaging studies showed normal pelvicalyceal system without obstruction. Seven patients, who had undergone Anderson-Hynes dismembered pyeloplasty for unilateral UPJ obstruction without crossing vessels, represented the UPJ obstruction. Mean age was $28 \pm 10$ years ( 5 male, 2 females; age range was 18-35 years). Imaging studies showed dilated pelvicalyceal system, obstructive pattern of the clearance curve and $\mathrm{T} 1 / 2$ greater than 20 min when evaluated with diuretic renogram, split renal function $<30 \%$. The surgical specimens were composed of part of the dilated renal pelvis, the UPJ segment, and portion of the proximal ureter. The 12 surgical specimens were processed for histological, IHC, TEM studies. The institutional review board (IRB) approved the present study (Research Ethics Committee: TBRI-Protocol No: PT 536). The study was conducted in compliance with the relevant laws and 
regulations, good clinical practice, and ethical principles as described in the World Medical Association's Declaration of Helsinki. Requiring patients to provide informed consents was waived by the IRB because of the retrospective feature of the present study.

\section{Histopathology}

Excised specimens from ureter, pelviureteric junction and renal pelvis were immediately fixed in a $10 \%$ formalin solution, processed in a tissue processor (Thermo Scientific STP 120 Spin, UK) and embedded in paraffin. Sections, 4 microns thick, were then stained with haematoxylin and eosin (H\&E) stain to examine histopathologic changes. Gomori's modified Masson's trichrome stain was used to assess the fibrosis. The examined parts were the proximal ureter, UPJ segment, and renal pelvis. Standard H\&E were primarily done to define the area in the segment to be compared in every studied part. The examination with Gomori's modified Masson's trichrome stain showed the distribution of collagen fibres in different segments of UUT in normal and obstructed cases.

\section{Immunohistochemistry}

Immunohistochemistry was performed on 5 microns thick sections of formalin-fixed and paraffin-embedded tissue samples. Sections were picked on charged glass slides and deparaffinised, hydrated, then treated for antigen retrieval at a high $\mathrm{pH}$ $(\mathrm{pH}$ 8) using an automated immunostainer (Dako, Denmark). Rabbit polyclonal anti-CD117 (c-kit) antibodies (CD 117, Cat. No. A4502, Dako, Denmark) at dilution 1:200 were used to label the Cajal cells. Goat anti-rabbit biotinylated immunoglobulins/HRP (Cat. No. P0448, Dako, Denmark) were used at dilution 1:300. Streptavidin-biotin-peroxidase complex and peroxidase-DAB (3,3'diaminobenzidine) (Dako, Denmark) detection method was preformed according to the manufacturer's instructions. Sections were counterstained with Mayer's haematoxylin. Positive and negative control slides were included in each run. As a negative control, a tissue section was processed as described but with the primary antibody omitted.

\section{Transmission electron microscopy}

Immediately following surgical excision, samples from the three (blinded) specimens were cut into $1 \times 1 \mathrm{~mm}$ pieces, fixed in $2.5 \%$ glutaraldehyde in cacodylate buffer for $2 \mathrm{~h}$ at $4^{\circ} \mathrm{C}$. The tissues were then washed in cacodylate-sucrose buffer and post- fixed for $1 \mathrm{~h}$ at $4^{\circ} \mathrm{C}$ in $2 \%$ osmium tetroxide. After dehydration in graded ethanol, the samples were impregnated in Epon 812 substitute (EMBed-812 Kit, Electron Microscopy Science, USA) at room temperature, and polymerised at $60^{\circ} \mathrm{C}$ for $48 \mathrm{~h}$. Semi-thin sections were cut, stained with methylene blue-azure II, and examined by light microscopy to choose the region of interest for ultrathin sectioning. The ultrathin sections were then prepared using an Ultra cut R ultramicrotome (Leica, Vienna, Austria), double stained with uranyl acetate and lead citrate. Cellular ultrastructural morphological characterisation was examined at $80 \mathrm{kV}$ with a Philips EM $208 \mathrm{~S}$ electron microscope (Philips Optics, Eindhoven, The Netherlands). Identification and differentiation of telocytes and Cajal was done according to the description of different authors.

\section{RESULTS}

Distribution of Cajal cells in normal upper urinary tract and in ureteropelvic junction obstruction (UPJO). The study was done on 5 normal upper urinary tracts and 7 cases with UPJO by IHC. Immunostaining with c-kit to demonstrate the distribution of Cajal cells showed that the distribution was different and specific to each segment in both normal and obstructed UUT. Cajal cells were demonstrated in the muscular layer of UUT in normal and UPJ obstruction. In normal UUT, high density was demonstrated in the proximal ureter, excess in renal pelvis, and moderate in the UPJ segment. In obstructed UUT, high density of Cajal cells was demonstrated in the proximal ureter, moderate density in renal pelvis, but in the UPJ segment the cells were scant or absent (Fig. 1).

Collagen to smooth muscle ratio in normal upper urinary tract and UPJO. The study by light microscopy using H\&E and eosin stain as well as Gomori's modified Masson's trichrome stain showed that in normal UUT the collagen/muscle ratio was 2.3 for the proximal ureter, 1.5 for the UPJ segment, and 1 for the renal pelvis. The collagen/muscle ratio in UPJ obstruction showed that, compared to normal UUT, there was increased collagen in the UPJ segment, moderate collagen distribution in the renal pelvis, while the proximal ureter had an identical ratio (Fig. 1).

Telocytes, Cajal cells, smooth muscle cells, fibroblasts, collagen, and stem cells detection by TEM. Transmission electron microscopy examination demonstrated the presence of telocytes (Fig. 2), and Cajal cells (Fig. 3). Stem cells, fibroblasts, collagen 


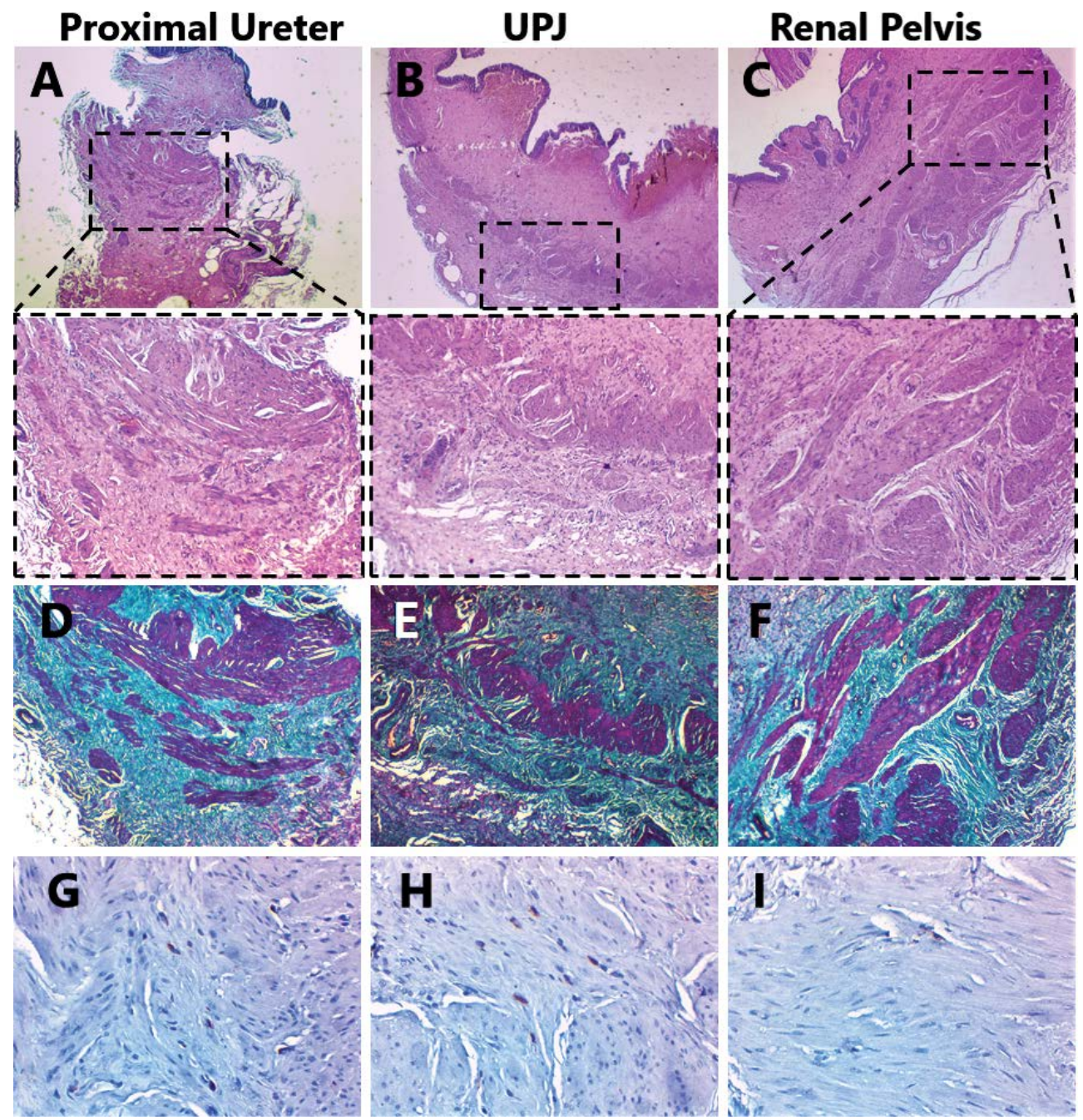

Figure 1. Morphological pattern of collagen to smooth muscles distribution in normal upper urinary tract, sections were stained with haematoxylin and eosin stain and Gomori's stain (A-F). Pattern of distribution of Cajal cells in normal upper urinary tract demonstrated with c-kit immunohistochemistry (G-I); Left column represents the proximal ureter, middle column represents ureteropelvic junction (UPJ) segment, right column represents renal pelvis. Upper row: Haematoxylin and eosin stained sections from muscularis propria with high insert box; proximal ureter (A), UPJ segment (B) and renal pelvis (C). Scale bar $=2 \mathrm{~mm}$. Middle row: Gomori's trichrome stained sections showing smooth muscle bundles of the muscularis propria with collagen fibres. (collagen/muscle ratio of 2.3 for the proximal ureter (D) 1.5 for UPJ segment (E), and 1 for the renal pelvis (F). Scale bar $=2 \mathrm{~mm}$. Lower row: Immunohistochemical staining with c-kit (CD 117) showing distribution of interstitial cells of Cajal in the upper urinary tract. The proximal ureter has the highest condensation of Cajal cells (G), the UPJ has a considerable density of Cajal cells (H), few cells are in the renal pelvis (I). Scale bar $=500 \mu \mathrm{m}$.

fibres, and myoblasts were demonstrated in all specimens of normal UUT and UPJO (Fig. 4). In the normal UUT, they were in excess in proximal ureter and renal pelvis, but moderately expressed in the UPJ segment. In UPJO, these interstitial cells were few in the renal pelvis, rare in the UPJ segment but in excess in the proximal ureter.

Correlation between density of Cajal cells and collagen/muscle ratio in normal UUT and UPJO. Distribution of interstitial cells in proximal ureter and renal pelvis in obstructed cases was similar to normal. Distribution of density of Cajal cells was correlated to the ratio of collagen to muscle fibres: the more muscle fibres in relation to collagen, the higher the density of Cajal cells. This finding was obvious in proximal ureter and renal pelvis in normal UUT. Diminished distribution of smooth muscle cells in the UPJ segment was associated with relative low density of Cajal cells and telocytes.

\section{DISCUSSION}

Cajal cells which are c-kit positive were demonstrated in this study in the muscular layer of normal UUT and in UPJO. Identification and characterisation 

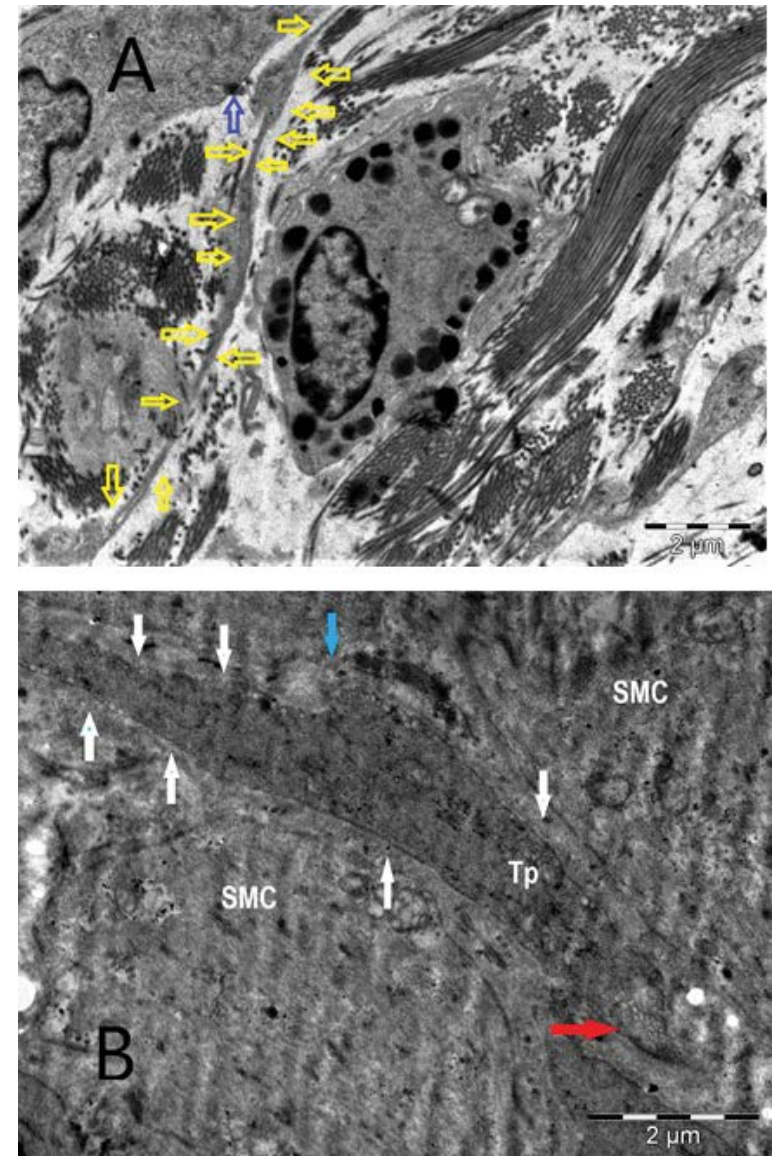

Figure 2. Transmission electron microscopy of the muscle layer of the ureteropelvic junction in normal upper urinary tract. A. Telocytes cytoplasmic process (telopode) (indicated with yellow arrows). The blue arrow indicates a contact between a telocyte and a myofibroblast. The telopode is characterised by a long slender cytoplasmic elongation that gets into contact with interstitial and smooth muscle cells; B. Telopode (Tp) is intervening between two smooth muscle cells (SMC; white arrow). The blue arrow indicates a group of caveolae, the white arrow is an attachment site between the telopode and smooth muscle cell (red arrow). Scale bar: $\mathrm{A}=2 \mu \mathrm{m} ; \mathrm{B}=2 \mu \mathrm{m}$.

of these cells and their differentiation from other interstitial cells were in accordance with descriptions by previous studies on the upper urinary tract using IHC and TEM $[3-9,11,20]$. In our study, we showed that, in the normal UUT, Cajal cells were densely present in the proximal ureter, excessively in the renal pelvis, and moderately dense in the UPJ segment. In the UPJO, we demonstrated the presence of Cajal cells in the UPJ segment in few numbers, in moderate numbers in the renal pelvis, and in high numbers in the proximal ureter. Our results differ from previous studies $[3,4,7,15,21]$ where only the UPJ segment was examined and changes in proximal ureter and renal pelvis were not considered. Eken et al. [4] searching for Cajal cells in the UPJ segment in UPJO in paediatric patients, found out that the Cajal
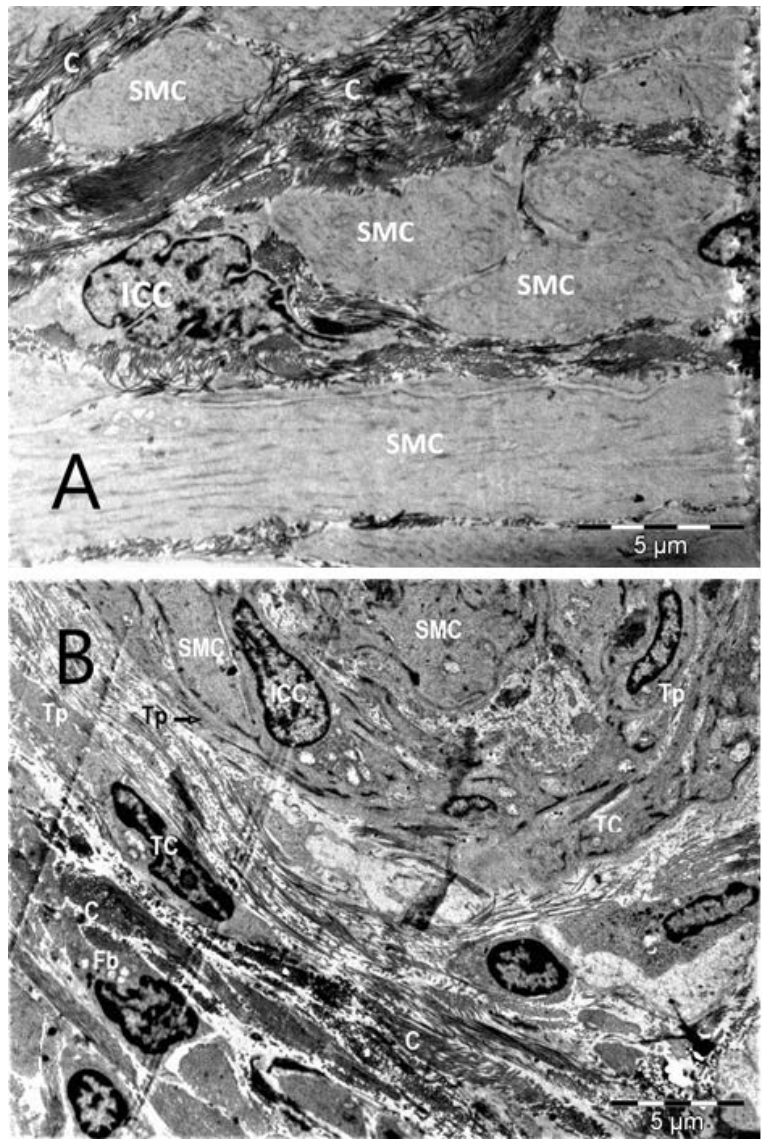

Figure 3. Transmission electron microscopy of muscle layer of the ureteropelvic junction in normal upper urinary tract. A. Interstitial cell of Cajal (ICC) is located between longitudinal and transverse muscle layer, it is characterised by notched nucleus and scant cytoplasm with cytoplasmic extension intervening between the smooth muscle cells (SMC). The segment shows properly arranged SMC, few collagen (C); B. Telocytes (TC), telopodes (Tp), and interstitial cells of Cajal (ICC) are existing in-between smooth muscle cells $(\mathrm{SMC})$, there are scattered collagen fibres (C). Scale bar: $\mathrm{A}=2 \mu \mathrm{m} ; \mathrm{B}=2 \mu \mathrm{m}$.

cells were either rare or absent. Our study confirmed their presence in the UPJ segment in UPJO, although not in the same density as in the normal UPJ segment. The difference in findings would be attributed to different age groups, as Eken et al. [4] studied the paediatric age group, while our study was applied to adults.

Examining the whole UUT in both normal and obstructed cases, we found that the three anatomical divisions express the same cells in different density, i.e. on cellular basis they are one unit. While in the past their division was based on shape and configuration, our concept is that the UUT is one entity and each part would play a role in the pathogenesis of UPJO.

Our study showed that the relationship between muscle density and collagen differed from one seg- 

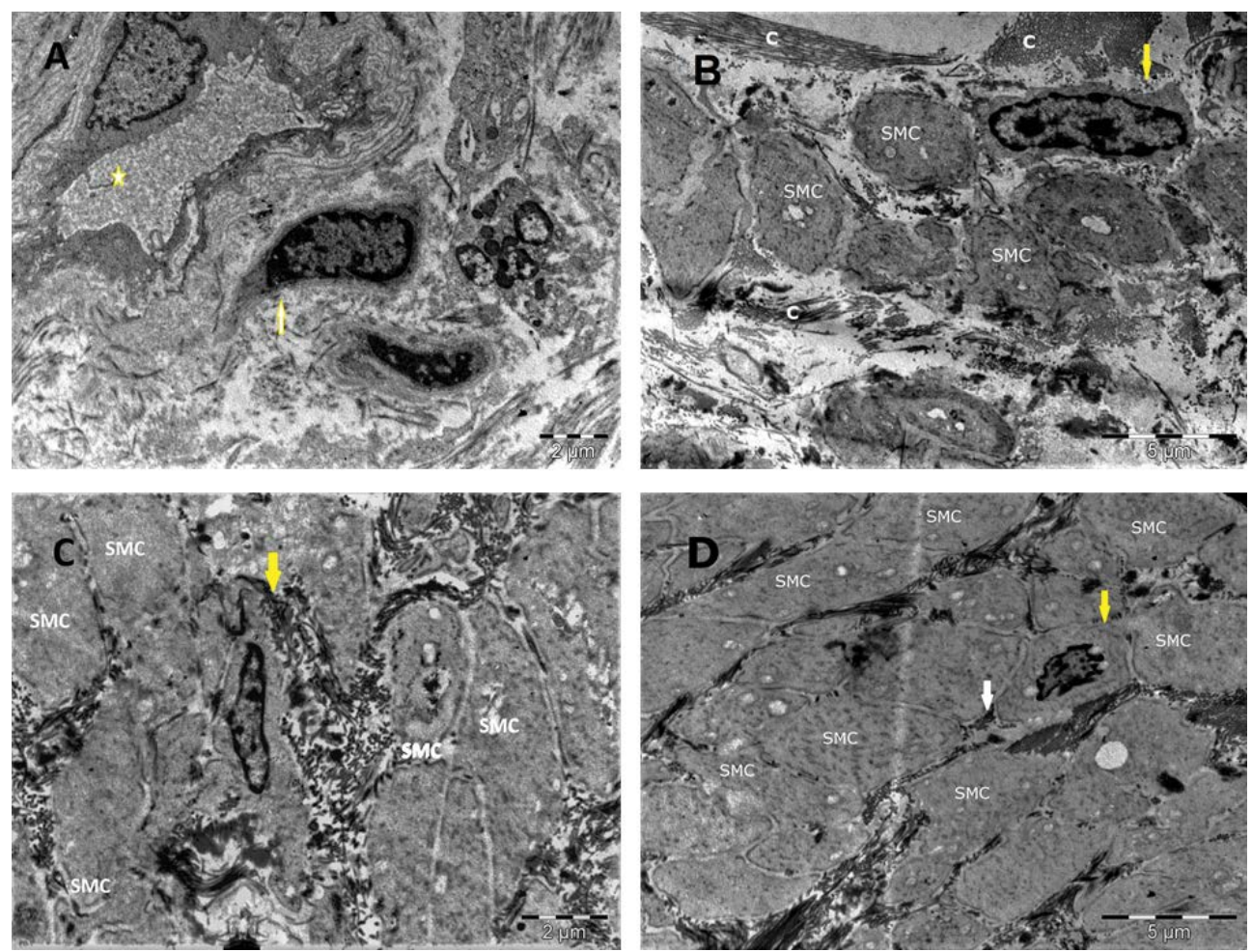

Figure 4. A. Dormant stem cell resident by the nearby capillary (arrow). It shows notched nucleus as well as rough endoplasmic reticulum alongside the nucleus. It also lacks the elongated processes of the telocytes, capillary vessel (asterisk). Scale bar $=2 \mu \mathrm{m} ; \mathbf{B}$. Mesenchymal stem cells (yellow arrow), with scanty rim and obscured detailed cytoplasm, and polymorphic nuclei with deep notches. Scale bar $=5 \mu \mathrm{m}$; C. Myofibroblast (yellow arrow) showing peripheral myofilaments with focal densities, and a dense basement membrane-like material. They are surrounded by matrix collagen fibres, smooth muscle cells (SMC) are in close cell-to-cell adhesion and few collagen (C) fibres intervening in the contact areas. Scale bar $=2 \mu \mathrm{m}$; D. Myocyte (yellow arrow). The white arrow indicates collagen fibres of connective tissue, smooth muscles are in close contact to each other (SMC). Scale bar $=5 \mu \mathrm{m}$.

ment to the other. In both normal and obstructed UUT, the muscle fibres were of higher concentration than the collagen in proximal ureter, renal pelvis, and UPJ segment, respectively.

Transmission electron microscopy of the normal UUT and UPJ obstruction showed the presence of telocytes in the proximal ureter, renal pelvis, and UPJ segment. Our work examined the three parts of UUT and confirmed the presence of telocytes. Previous reports by Zheng et al. [22], Qi et al. [13], Vannucchi et al. [17, 18], and Gevaert et al. [6] supported our findings. In our study on different parts of the UUT by TEM, we demonstrated the presence of stem cells, in addition to fibroblasts, myoblasts, telocytes, and Cajal cells. Previous studies on the interstitial cells of the UUT concentrated on one cell type, our study investigated all cell types and demonstrated their existence in normal and obstructed UUT.

\section{CONCLUSIONS}

Telocytes and Cajal cells were demonstrated with different density in the muscular layers of the UPJ segment, the renal pelvis, and the proximal ureter in normal and obstructed upper urinary tract secondary to UPJ obstruction. The low density of Cajal cells and increased collagen fibrils in the UPJ segment, in addition to the low density of Cajal cells in renal pelvis of UPJ obstruction, would be attributed to the aetiology of UPJ obstruction.

\section{Conflict of interest: None declared}

\section{REFERENCES}

1. Cajal SR. Histologie du système nerveux de l'homme et des vertébrés. Maloine (Paris). 1909; 2: 891-942, doi: 10.5962/bhl.title.48637.

2. Cretoiu SM, Popescu LM. Telocytes revisited. Biomol Concepts. 2014; 5(5): 353-369, doi: 10.1515/bmc-2014-0029, indexed in Pubmed: 25367617.

3. David SG, Cebrian C, Vaughan ED, et al. c-kit and ureteral peristalsis. J Urol. 2005; 173(1): 292-295, doi: 10.1097/01. ju.0000141594.99139.3d, indexed in Pubmed: 15592099.

4. Eken A, Erdogan S, Kuyucu Y, et al. Immunohistochemical and electron microscopic examination of Cajal cells in ureteropelvic junction obstruction. Can Urol Assoc J. 2013; 
7(5-6): E311-E316, doi: 10.5489/cuaj.11293, indexed in Pubmed: 23069698.

5. Gevaert T, De Vos R, Everaerts W, et al. Characterization of upper lamina propria interstitial cells in bladders from patients with neurogenic detrusor overactivity and bladder pain syndrome. J Cell Mol Med. 2011; 15(12): 2586-2593, doi: 10.1111/j.1582-4934.2011.01262.x, indexed in Pubmed: 21251216.

6. Gevaert T, De Vos R, Van Der Aa F, et al. Identification of telocytes in the upper lamina propria of the human urinary tract. J Cell Mol Med. 2012; 16(9): 2085-2093, doi: 10.1111/j.15824934.2011.01504.x, indexed in Pubmed: 22151349.

7. Koleda P, Apoznanski W, Wozniak Z, et al. Changes in interstitial cell of Cajal-like cells density in congenital ureteropelvic junction obstruction. Int Urol Nephrol. 2012; 44(1): 7-12, doi: 10.1007/s11255-011-9970-5, indexed in Pubmed: 21547467.

8. Lang RJ, Klemm MF. Interstitial cell of Cajal-like cells in the upper urinary tract. J Cell Mol Med. 2005; 9(3): 543-556, doi: 10.1111/j.1582-4934.2005.tb00487.x, indexed in Pubmed: 16202204.

9. Maeda H, Yamagata A, Nishikawa S, et al. Requirement of c-kit for development of intestinal pacemaker system. Development. 1992; 116(2): 369-375, indexed in Pubmed: 1283735.

10. Petre N, Rusu MC, Pop F, et al. Telocytes of the mammary gland stroma. Folia Morphol. 2016; 75(2): 224-231, doi: 10.5603/FM.a2015.0123, indexed in Pubmed: 26711648.

11. Popescu LM, Ciontea SM, Cretoiu D. Interstitial Cajal-like cells in human uterus and fallopian tube. Ann N Y Acad Sci. 2007; 1101: 139-165, doi: 10.1196/annals.1389.022, indexed in Pubmed: 17360808.

12. Popescu LM, Faussone-Pellegrini MS. TELOCYTES a case of serendipity: the winding way from Interstitial Cells of Cajal (ICC), via Interstitial Cajal-Like Cells (ICLC) to TELOCYTES. J Cell Mol Med. 2010; 14(4): 729-740, doi: 10.1111/j.1582-4934.2010.01059.x, indexed in Pubmed: 20367664.

13. Qi G, Lin $M, X u M$, et al. Telocytes in the human kidney cortex. J Cell Mol Med. 2012; 16(12): 3116-3122, doi: 10.1111/j.1582-4934.2012.01582.x, indexed in Pubmed: 23241355.

14. Sergeant GP, Thornbury KD, McHale NG, et al. Interstitial cells of Cajal in the urethra. J Cell Mol Med. 2006; 10(2): 280-291, doi: 10.1111/j.1582-4934.2006.tb00399.x, indexed in Pubmed: 16796799.

15. Solari V, Piotrowska AP, Puri P. Altered expression of interstitial cells of Cajal in congenital ureteropelvic junction obstruction. J Urol. 2003; 170(6 Pt 1): 2420-2422, doi: 10.1097/01. ju.0000097401.03293.f0, indexed in Pubmed: 14634443.

16. van der Aa F, Roskams T, Blyweert W, et al. Identification of kit positive cells in the human urinary tract. J Urol. 2004; 171(6 Pt 1): 2492-2496, doi: 10.1097/01. ju.0000125097.25475.17, indexed in Pubmed: 15126883.

17. Vannucchi MG, Traini C, Guasti D, et al. Telocytes subtypes in human urinary bladder. J Cell Mol Med. 2014; 18(10): 2000-2008, doi: $10.1111 / \mathrm{jcmm} .12375$, indexed in Pubmed: 25139461.

18. Vannucchi MG, Traini C. Interstitial cells of Cajal and telocytes in the gut: twins, related or simply neighbor cells? Biomol Concepts. 2016; 7(2): 93-102, doi: 10.1515/bmc2015-0034, indexed in Pubmed: 26992201.

19. Vannucchi MG. The telocytes: ten years after their introduction in the scientific literature. An update on their morphology, distribution, and potential roles in the gut. Int J Mol Sci. 2020; 21(12), doi: 10.3390/ijms21124478, indexed in Pubmed: 32599706.

20. Yamataka A, Ohshiro K, Kobayashi $H$, et al. Abnormal distribution of intestinal pacemaker (C-KIT-positive) cells in an infant with chronic idiopathic intestinal pseudoobstruction. J Pediatr Surg. 1998; 33(6): 859-862, doi: 10.1016/ s0022-3468(98)90660-1.

21. Yang $X$, Zhang $Y$, Hu J. The expression of Cajal cells at the obstruction site of congenital pelviureteric junction obstruction and quantitative image analysis. J Pediatr Surg. 2009; 44(12): 2339-2342, doi: 10.1016/j.jpedsurg.2009.07.061, indexed in Pubmed: 20006022.

22. Zheng $\mathrm{Y}$, Zhu T, Lin M, et al. Telocytes in the urinary system. J Transl Med. 2012; 10: 188, doi: 10.1186/1479-5876-10188, indexed in Pubmed: 22963412. 